\title{
Sex-specific differences in diabetes prevention: a systematic review and meta-analysis
}

\author{
Anna Glechner • Jürgen Harreiter • Gerald Gartlehner • Sonja Rohleder • \\ Alexander Kautzky • Jaakko Tuomilehto • Megan Van Noord • \\ Angela Kaminski-Hartenthaler • Alexandra Kautzky-Willer
}

Received: 30 July 2014 / Accepted: 15 October 2014 /Published online: 3 December 2014

(C) Springer-Verlag Berlin Heidelberg 2014

\begin{abstract}
Aims/hypothesis In people with prediabetes, lifestyle interventions and glucose-lowering medications are effective in preventing the progression to type 2 diabetes. It is unclear whether differences in treatment effects between men and
\end{abstract}

Anna Glechner and Jürgen Harreiter contributed equally to this study.

Electronic supplementary material The online version of this article (doi:10.1007/s00125-014-3439-x) contains peer-reviewed but unedited supplementary material, which is available to authorised users.

A. Glechner $(\varangle) \cdot$ G. Gartlehner · M. Van Noord •

A. Kaminski-Hartenthaler

Department for Evidence-based Medicine and Clinical

Epidemiology, Danube University Krems,

Dr.-Karl-Dorrek-Strasse 30, 3500 Krems, Austria

e-mail: anna.glechner@donau-uni.ac.at

J. Harreiter $\cdot$ S. Rohleder $\cdot$ A. Kautzky $\cdot$ A. Kautzky-Willer Gender Medicine Unit, Department of Internal Medicine III, Division of Endocrinology and Metabolism, Medical University of Vienna,

Vienna, Austria

G. Gartlehner

RTI-UNC Evidence-based Practice Center, RTI-International,

Research Triangle Park, NC, USA

J. Tuomilehto

Department of Psychiatry and Psychotherapy, Medical University of

Vienna, Vienna, Austria

J. Tuomilehto

Diabetes Prevention Unit, National Institute for Health and Welfare,

Helsinki, Finland

J. Tuomilehto

Diabetes Research Group, King Abdulaziz University,

Jeddah, Saudi Arabia

Present address:

A. Kautzky

Department of Psychiatry and Psychotherapy, Medical University of

Vienna, Vienna, Austria women need to be taken into consideration when choosing a preventive strategy for an individual person.

Methods We systematically searched PubMed, the Cochrane Library, EMBASE, CINAHL, Web of Science, and reference lists of pertinent review articles from 1980 to June 2013. We conducted random effects meta-analyses of published and unpublished data to determine differences of treatment effects between men and women.

Results Twelve randomised control trials (RCTs) provided sexspecific information on treatment effects. Compared with usual care, men and women who received lifestyle interventions had a lower rate of progression to type 2 diabetes (RR 0.60 [95\% CI $0.35,1.05]$ after 1 year; RR 0.63 [95\% CI 0.51, 0.79] after 3 years); greater weight reduction $(-2.45 \mathrm{~kg}$; [95\% CI -3.56 , $-1.33 \mathrm{~kg}]$ after 3 years); and greater reductions of fasting plasma glucose $(-0.31 \mathrm{mmol} / 1[95 \% \mathrm{CI}-0.48,-0.15]$ after 3 years) and $2 \mathrm{~h}$ post-challenge-glucose $(-0.68 \mathrm{mmol} / 1$ [ $95 \% \mathrm{CI}$ $-1.03,-0.34]$ after 3 years). No statistically significant differences in treatment effects between men and women were apparent for any outcomes ( $p$ values of all comparisons $\geq 0.09$ ). Conclusions/interpretation Our study emphasises the importance of preventive interventions in people with prediabetes and indicates no differences of beneficial preventive effects on the incidence of type 2 diabetes and weight gain between men and women.

Keywords Diabetes prevention · Glucose-lowering agents - Lifestyle intervention - Meta-analysis . Prediabetes $\cdot$ Sex $\cdot$ Systematic review

$\begin{array}{ll}\begin{array}{l}\text { Abbreviations } \\ \text { CANOE }\end{array} & \begin{array}{l}\text { CAnadian Normoglycemia Outcomes } \\ \text { Evaluation }\end{array} \\ \text { Finnish DPS } & \text { Finnish Diabetes Prevention Study } \\ \text { IFG } & \begin{array}{l}\text { Impaired fasting glucose } \\ \text { IGT }\end{array} \\ \text { Impaired glucose tolerance }\end{array}$

Abbreviations

CAnadian Normoglycemia Outcomes Evaluation Impaired fasting glucose Impaired glucose tolerance 
RCT Randomised controlled trial

STOP-NIDDM Study TO Prevent Non-Insulin Dependent Diabetes Mellitus
US DPP United States Diabetes Prevention Program

control of diabetes mellitus, lifestyle interventions and glucose-lowering agents according to our inclusion criteria. We limited electronic searches to 'adult 19+years' and 'human', 'English' and 'German'. The complete search strategy can be found in the electronic supplementary material [ESM] Methods. To minimise retrieval bias, we also used semi-automatic manual searches of reference lists of pertinent review articles and letters to the editor employing the Scopus citation database (www.scopus. com) [9].

Early detection of prediabetes offers the possibility of using lifestyle or pharmacological interventions to prevent or slow the progression to type 2 diabetes. Numerous studies provide evidence that lifestyle interventions such as changes in diet and regular physical activity $[1,2]$, or oral glucose-lowering drugs such as alpha-glucosidase inhibitors, metformin, or glitazones [3] and insulin [4] can delay or prevent the onset of type 2 diabetes in people with prediabetes. To our knowledge, no studies have assessed systematically whether sexspecific differences need to be considered for interventions used to prevent type 2 diabetes in people with prediabetes.

Although the lifetime risk of diabetes is similar in men and women, important differences with respect to onset age, detection and burden of type 2 diabetes between men and women exist. For example, middle-aged men have a higher prevalence of type 2 diabetes than women of the same age, while elderly women have a higher prevalence than men $[5$, 6]. Furthermore, impaired glucose tolerance (IGT) without impaired fasting glucose (IFG) is more common in women than in men. As a consequence, detection rates of prediabetes are lower in women than in men because OGTTs are more labour intense and are thus less often performed than fasting glucose tests [7]. Studies suggest that prediabetic men and women also differ in insulin resistance with women showing overall better insulin sensitivity [8].

The objective of our systematic review was to assess differences in effectiveness and risk of harms of commonly used interventions to prevent type 2 diabetes between men and women diagnosed with prediabetes.

\section{Methods}

The study was registered in PROSPERO (www.crd.york.ac. uk/prospero/) under the following registration number: PROSPERO 2012:CRD42012003102.

\section{Data sources}

We searched MEDLINE (via PubMed), the Cochrane Library, EMBASE, CINAHL, International Pharmaceutical Abstracts (IPA) and Web of Science from 1980 to 11 June 2013. We used medical subject headings (MeSH) and keywords as search terms and combined specific terms for prevention and

\section{Study selection}

Two persons independently reviewed abstracts and full-text articles. Eligibility criteria for studies were defined a priori and are presented in ESM Table 1. We included randomised controlled trials (RCTs) that compared lifestyle interventions with treatment as usual or glucose-lowering agents, or glucose-lowering agents with active control or placebo. Our population of interest comprised people with prediabetes as defined by the ADA or the WHO [10-12]. At the time when most studies were conducted, the ADA defined prediabetes as IFG of 5.6 to $6.9 \mathrm{mmol} / \mathrm{l}$ and/or IGT $(2 \mathrm{~h}$ post-challenge glucose) of 7.8 to $11.0 \mathrm{mmol} / \mathrm{l}$ with a $75 \mathrm{~g}$ OGTT. Because our literature searches went back to 1980 , we also accepted older studies [13-16] that defined prediabetes according to the WHO in 1985, i.e. IGT with or without IFG [12]. The ADA and WHO classifications used fasting plasma glucose levels of $7.8 \mathrm{mmol} / \mathrm{l}$ as the lower threshold for diabetes until 1997 and 1999, respectively.

Outcomes of interest were sex-specific differences of the incidence of type 2 diabetes, reduction of fasting plasma glucose and $2 \mathrm{~h}$ post-challenge glucose, weight loss, health related quality of life, diabetes-associated comorbidity and mortality. Studies that analysed only women with prior gestational diabetes were excluded due to the lack of a correlating male control group. We dually reviewed all citations and resolved disagreements about inclusion or exclusion by consensus or by involving a third reviewer.

Data extraction and quality assessment

We used standardised data abstraction forms into which trained reviewers abstracted data from each study and assigned an initial rating of the risk of bias. A senior reviewer checked the data for correctness and evaluated risk of bias ratings. If publications did not provide information on differences in treatment effects between men and women, but otherwise fulfilled our inclusion criteria, we contacted authors to request additional data. To assess the risk of bias of RCTs, we used predefined criteria based on the Cochrane Risk of Bias tool (ratings: low - unclear - high risk of bias) [17]. 
Data synthesis and analyses

We contacted authors to release unpublished data on sexspecific differences if the published studies did not provide enough detail. Data of continuous outcomes are expressed as means compared with baseline \pm SD. We conducted metaanalyses if three or more studies that were similar with respect to populations and interventions provided data for quantitative analyses. We calculated either the RR of reducing diabetes incidence or the weighted mean difference of changes on fasting plasma glucose, $2 \mathrm{~h}$ post-challenge glucose and body weight.

For each meta-analysis, we conducted a test of heterogeneity $\left(I^{2}\right.$ statistic, Cochran's $q$-test $)$ and applied both a random and a fixed effects model. For all results, we report random effects models. To detect differences in treatment effects between men and women, we used subgroup analyses and statistically compared subgroup effects. If high heterogeneity was present $\left(I^{2}\right.$ statistic $\left.>60 \%\right)$ we explored the reasons for heterogeneity using meta-regressions.

We assessed publication bias using funnel plots, Egger's regression intercept and Kendall's S statistic. Given the small number of trials in some of our meta-analyses, these tests have low sensitivity to detect publication bias. All statistical analyses were conducted using Comprehensive Meta-Analysis, version 2.2.050 (www.meta-analysis.com/index.php).

\section{Grading quality of evidence}

We dually evaluated the quality of the body of evidence for each critical outcome of interest using an approach proposed by the Grading of Recommendations Assessment, Development and Evaluation (GRADE) working group [18]. The quality of evidence for each outcome or comparison that we graded incorporates scores on five domains: risk of bias, inconsistency, indirectness, imprecision and reporting bias; it can also reflect ratings for other domains that can be factored in when relevant (e.g. dose-response relationships). We used four grades to designate strength of evidence: high, moderate, low and very low. Grades reflect the quality of the body of evidence regarding differences in effectiveness and risk of harms between men and women. They do not refer to the general efficacy or effectiveness. We reconciled all disagreements in grades through consensus discussion.

\section{Results}

Our literature searches identified 2,543 relevant abstracts. We retrieved 304 full-text articles for more detailed examination. ESM Figure 1 depicts results of the searches and the study selection process. Eighteen RCTs (44 articles) met our eligibility criteria [1, 2, 13-15, 19-57]. Only three of those, however, published sex-specific results $[1,20,22,40]$. We contacted authors of the remaining 15 RCTs regarding sexspecific results of their studies. Authors of nine RCTs supplied unpublished sex-specific data upon request $[14,15,21,24,34$, $36,38,39,51]$.

The majority of the studies reported surrogate outcomes, such as laboratory values (fasting plasma glucose, $2 \mathrm{~h}$ postchallenge glucose) or incidence of type 2 diabetes. Change of body weight was the most commonly recorded health outcome. Four studies provided sex-specific results on morbidity and mortality rates $[2,14,15,21,26-34]$. ESM Table 2 summarises population and study characteristics (risk of bias and population characteristics at baseline) of the included studies. In the following sections, we summarise results on sex-specific differences of diabetes prevention by intervention.

\section{Lifestyle interventions}

Seven RCTs with more than 1,200 men and 970 women compared lifestyle interventions with treatment as usual [2, $14,15,26-39,48-51]$. Follow-up periods lasted up to 6 years.

Lifestyle interventions included regular dietary advice and instructions for physical activity. People in control groups received counselling about diabetes, verbal and written information about diet and exercise or consultation of a dietitian at the beginning of the study phase. Six studies provided sexstratified data on 1,644 men and women with prediabetes for meta-analyses of the effect of lifestyle interventions on diabetes incidence, body weight, fasting plasma glucose and $2 \mathrm{~h}$ post-challenge-glucose after 1 and 3 years of follow-up [2, 15, 28-39, 48-51].

Diabetes incidence We conducted meta-analyses of four RCTs [34-39] with data on 884 people with prediabetes to assess sex-specific differences of the effect of lifestyle interventions on the prevention of progression to type 2 diabetes. After 1 year, prediabetic people receiving lifestyle interventions had a numerically lower (albeit not statistically significant) risk of progressing to type 2 diabetes than people in the treatment as usual groups (RR 0.60 [95\% CI 0.35, 1.05]). Stratified analyses presented similar risk reductions in both men and women (RR men 0.53 [95\% CI 0.26, 1.10]; RR women 0.71 [95\% CI 0.31, 1.64]; $p=0.61$; Fig. 1).

After 3 years of follow-up, pooled results of five RCTs with a total of 893 men and 662 women with prediabetes presented a statistically significant reduction of the risk of progressing to type 2 diabetes for prediabetic people receiving lifestyle interventions compared with those under treatment as usual (RR 0.63 [95\% CI 0.51, 0.79]; Fig. 2) [2, 15, 28-37, 39, 48-51]. In absolute numbers, out of 1,000 people with prediabetes, at least 52 but up to 122 people can be prevented from progressing to type 2 diabetes with lifestyle interventions compared with treatment as usual. No statistically significant differences in the preventive effect of lifestyle interventions could be detected 
Fig. 1 Random effects metaanalysis showing the RR of developing type 2 diabetes after 1 year of lifestyle intervention compared with treatment as usual (control). The $p$ value for male vs female participants is 0.61 ; overall $I^{2}, 0 \%$. EDIPS, European Diabetes Prevention Study; SLIM, Study on Lifestyle intervention and Impaired glucose tolerance Maastricht

$\begin{array}{ll} & \text { Study name } \\ \text { Female } & \text { Brazilian LIS [38] } \\ \text { Female } & \text { EDIPS [39] } \\ \text { Female } & \text { SLIM Study [35-37] } \\ \text { Female } & \text { Zensharen Study [34] } \\ \text { Female } & \\ \text { Male } & \text { Brazilian LIS [38] } \\ \text { Male } & \text { EDIPS [39] } \\ \text { Male } & \text { SLIM Study [35-37] } \\ \text { Male } & \text { Zensharen Study [34] } \\ \text { Male } & \\ \text { Overall } & \end{array}$

between men and women (RR men 0.70 [95\% CI: 0.53, 0.91]; $\mathrm{RR}$ women 0.51 [95\% CI 0.35, 0.75]; $p=0.20)$.

The only study with a long-term follow-up (6 years), the Chinese Da Qing study (306 men and 257 women), reported similar treatment effects as the studies described above [14, $26,27]$. Overall, the incidence of type 2 diabetes was statistically significantly lower for prediabetic people who participated in one of three different lifestyle intervention groups than in those who received treatment as usual (RR diet vs treatment as usual 0.64 [95\% CI $0.5,0.8]$ ). No statistically significant sex-specific differences in treatment effects could be detected (Table 1).

Body weight Pooled results of three RCTs [35-39] showed that 1 year of lifestyle interventions was more effective in reducing body weight than treatment as usual. Overall, people with prediabetes receiving lifestyle interventions achieved an additional mean weight reduction of $-2.44 \mathrm{~kg}(95 \% \mathrm{CI}-3.45$, $-1.43 \mathrm{~kg}$ ) compared with those treated as usual. Stratified by sex, men and women had similar reductions in body weight (-2.29 kg vs $-2.65 ; p=0.74$; ESM Fig. 2).

Fig. 2 Random effects metaanalysis showing the RR of developing type 2 diabetes after 3 years of lifestyle intervention compared with treatment as usual (control). The $p$ value for male vs female participants is 0.20 ; overall $I^{2}, 0 \%$. EDIPS, European Diabetes Prevention Study; SLIM, Study on Lifestyle intervention and Impaired glucose tolerance Maastricht

$\begin{array}{ll} & \text { Study name } \\ & \\ \text { Female } & \text { EDIPS [39] } \\ \text { Female } & \text { Finnish DPS [2, 15, 28-33] } \\ \text { Female } & \text { IDDP -1 [48 -51] } \\ \text { Female } & \text { SLIM Study [35-37] } \\ \text { Female } & \text { Zensharen Study [34] } \\ \text { Female } & \\ \text { Male } & \text { EDIPS [39] } \\ \text { Male } & \text { Finnish DPS [2, 15, 28-33] } \\ \text { Male } & \text { IDDP -1 [48-51] } \\ \text { Male } & \text { SLIM Study [35-37] } \\ \text { Male } & \text { Zensharen Study [34] } \\ \text { Male } & \\ \text { Overall } & \end{array}$

\begin{tabular}{rrr}
\multicolumn{3}{c}{ RR, 95\% CI } \\
1.26 & 0.03 & 59.88 \\
1.29 & 0.20 & 8.39 \\
0.32 & 0.04 & 2.63 \\
0.69 & 0.23 & 2.03 \\
0.71 & 0.31 & 1.64 \\
0.59 & 0.03 & 12.49 \\
0.89 & 0.06 & 13.08 \\
0.19 & 0.02 & 1.49 \\
0.60 & 0.26 & 1.40 \\
0.53 & 0.26 & 1.10 \\
0.60 & 0.35 & 1.05
\end{tabular}

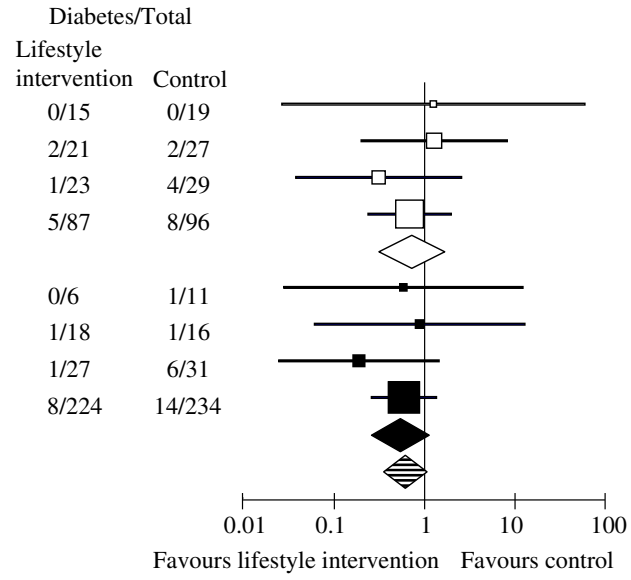

After 3 years, the mean weight reduction was $-2.45 \mathrm{~kg}$ $(95 \%$ CI $-3.56,-1.33 \mathrm{~kg})$. When stratified by sex, after 3 years, men in the lifestyle intervention arm lost $-2.78 \mathrm{~kg}$ $(95 \% \mathrm{CI}-4.00,-1.57 \mathrm{~kg})$, on average, and women lost $-0.6 \mathrm{~kg}(95 \% \mathrm{CI}-3.43,2.24 \mathrm{~kg} ; p=0.16$; Fig. 3) [2, 15, 28-33, 35-37, 39].

Fasting plasma glucose and 2 h post-challenge glucose ESM Figures 3 and 4 depict results of meta-analyses of three RCTs including 109 men and 134 women [35-39]. After 1 year, people with prediabetes receiving lifestyle interventions had a statistically significant reduction in fasting plasma glucose and $2 \mathrm{~h}$ post-challenge-glucose compared with those receiving treatment as usual (fasting plasma glucose $-0.28 \mathrm{mmol} / 1$ [95\% CI -0.47 , $-0.08] ; 2 \mathrm{~h}$ post-challenge-glucose $-0.63 \mathrm{mmol} / 1[95 \%$ CI $-1.08,-0.18])$. Men and women had similar reductions in fasting plasma glucose $(-0.45 \mathrm{vs}-0.26 \mathrm{mmol} / \mathrm{l}$; $p=0.57)$ and $2 \mathrm{~h}$ post-challenge-glucose $(-0.77$ vs $-0.56 ; p=0.67)$. ESM Figures 5 and 6 depict results of meta-analyses of three RCTs including 242 men

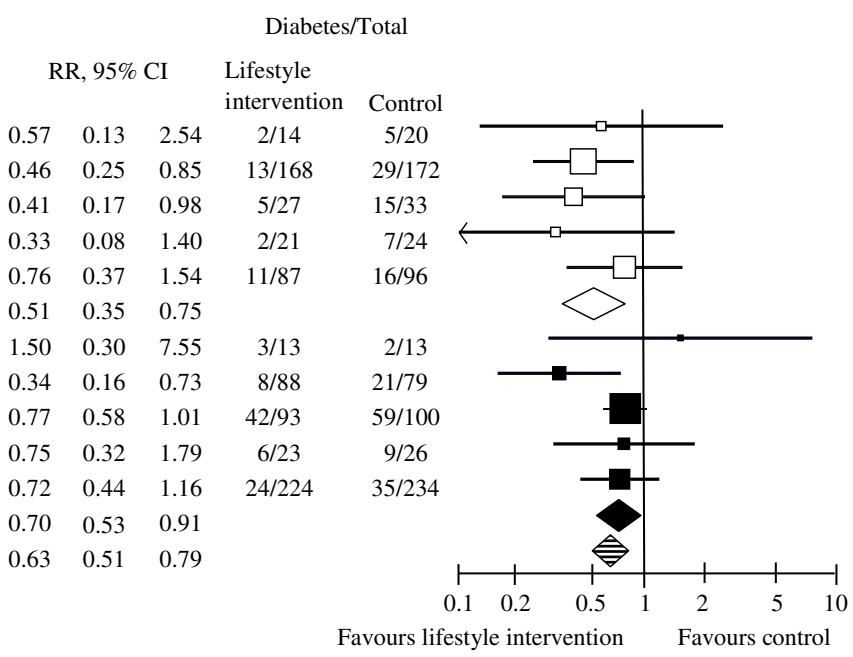




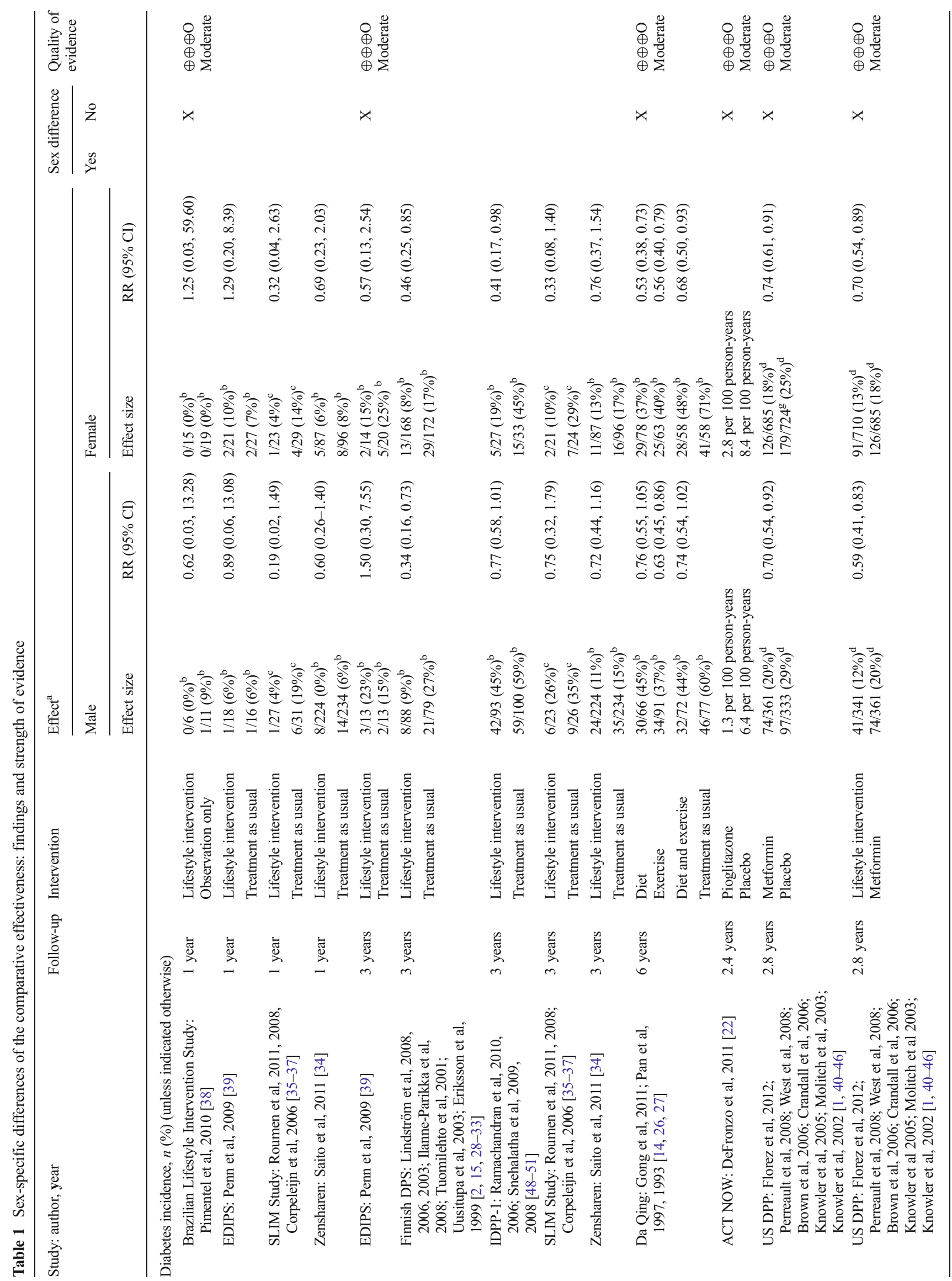




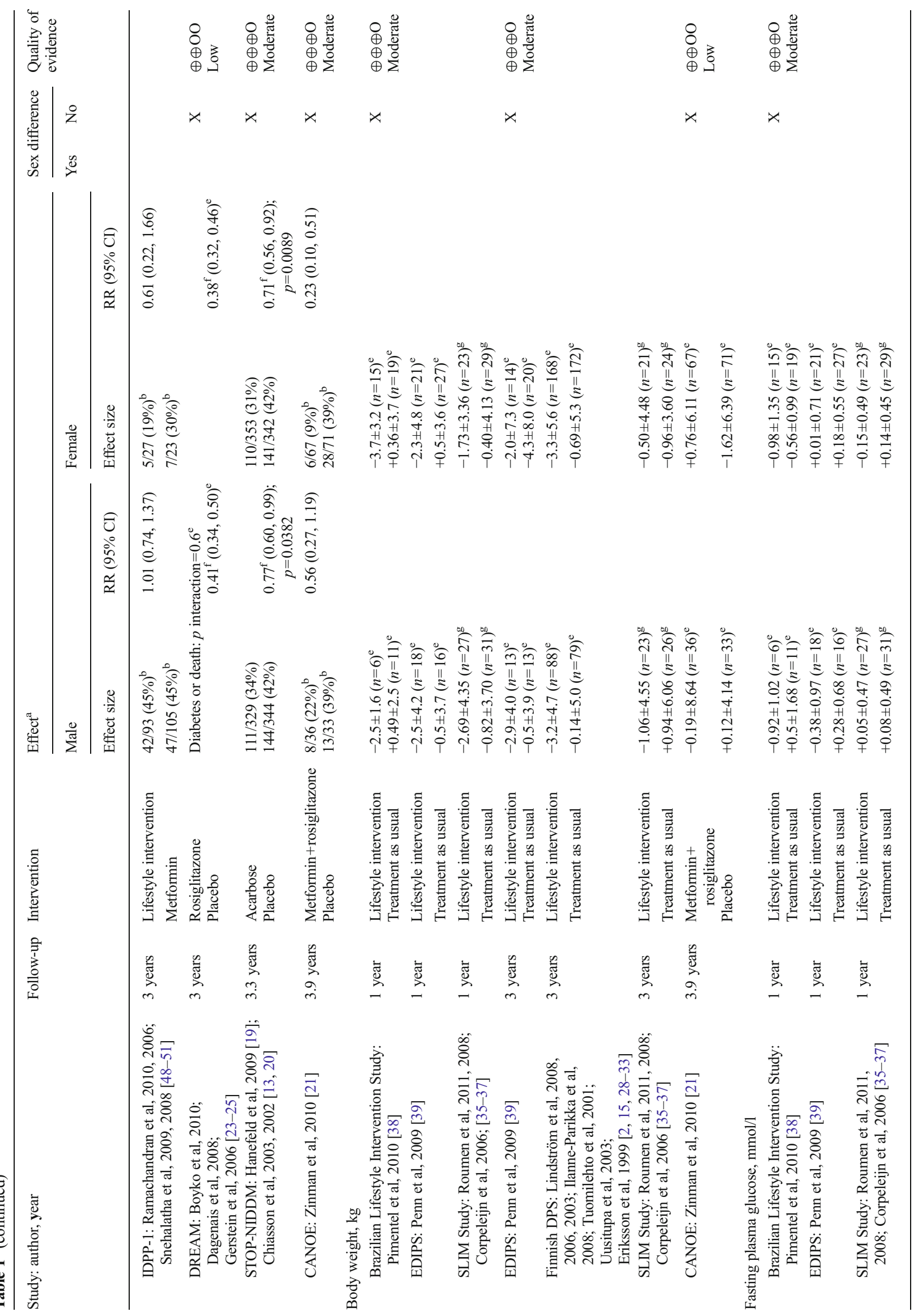




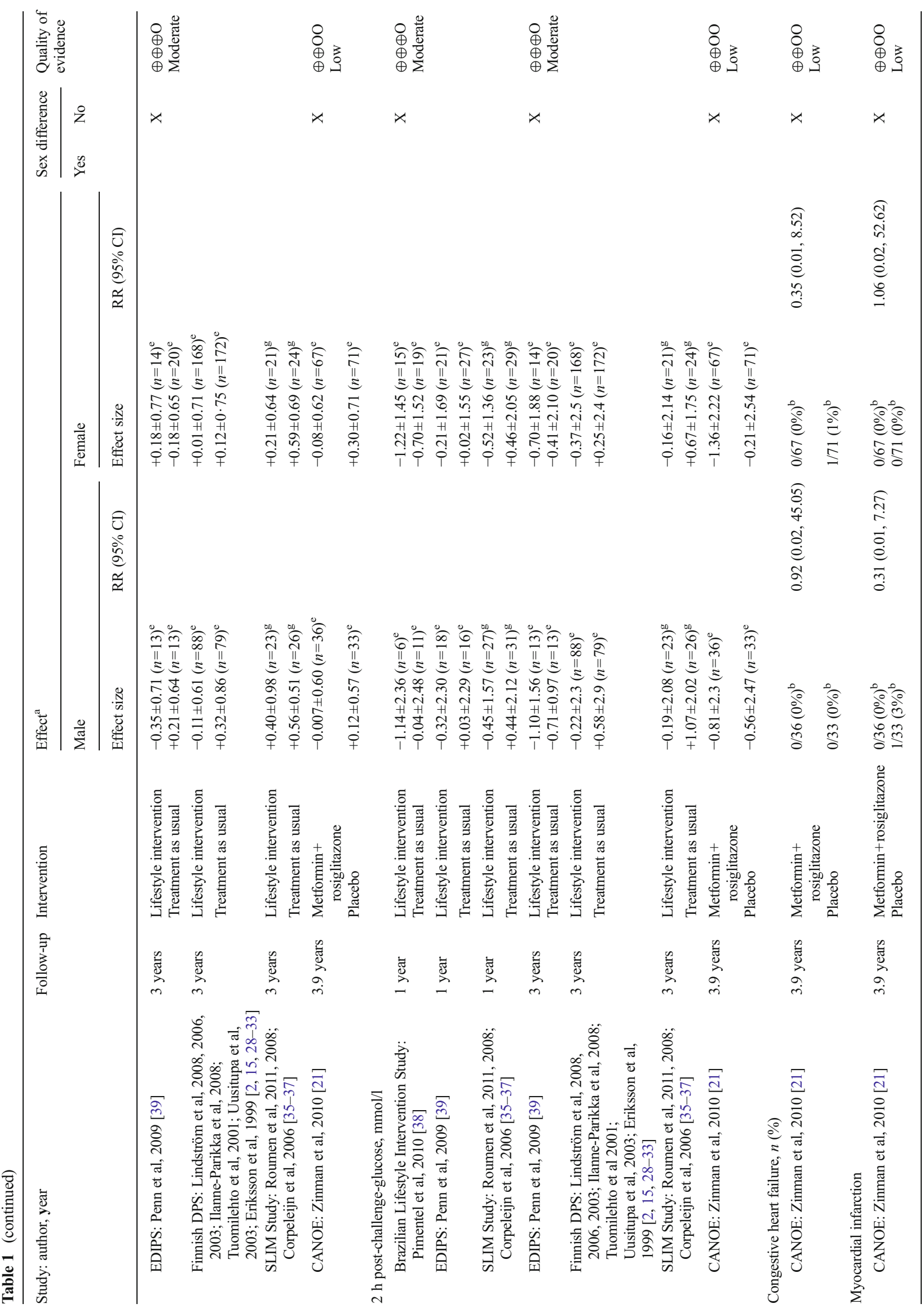




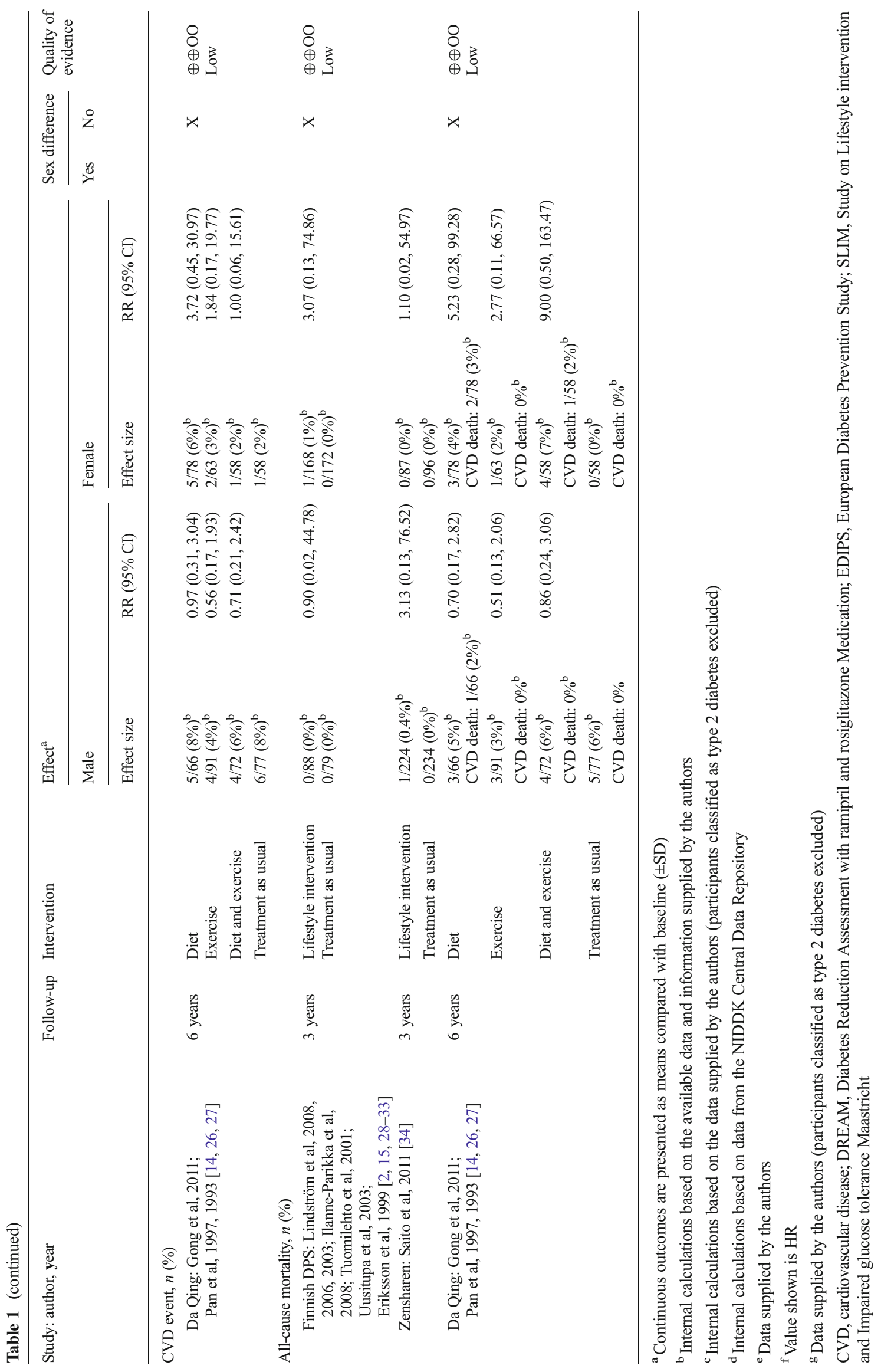


Fig. 3 Random effects metaanalysis showing weight change after 3 years of lifestyle intervention compared with treatment as usual (control). The $p$ value for male vs female participants is 0.16 ; overall $I^{2}$, 47\%. EDIPS, European Diabetes Prevention Study; SLIM, Study on Lifestyle intervention and Impaired glucose tolerance Maastricht

\begin{tabular}{llrrr} 
& \multicolumn{2}{c}{ Study name } & & \\
& & & \\
& & & \\
Female & EDIPS [39] & 2.30 & -2.97 & 7.57 \\
Female & Finnish DPS [2, 15, 28-33] & -2.61 & -3.77 & -1.45 \\
Female & SLIM Study [35-37] & 0.46 & -1.90 & 2.82 \\
Female & & -0.60 & -3.43 & 2.24 \\
Male & EDIPS [39] & -2.40 & -5.44 & 0.64 \\
Male & Finnish DPS [2, 15,28-33] & -3.06 & -4.53 & -1.59 \\
Male & SLIM Study [35-37] & -2.00 & -5.03 & 1.03 \\
Male & & -2.78 & -4.00 & -1.57 \\
Overall & & -2.45 & -3.56 & -1.33
\end{tabular}

Sample size

Lifestyle intervention Control

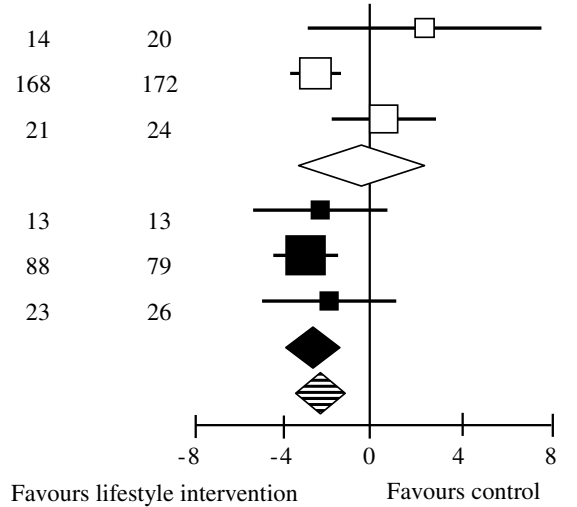

and 419 women. After 3 years of follow-up, participants in the lifestyle intervention group still had a greater reduction of fasting plasma glucose $(-0.31 \mathrm{mmol} / \mathrm{l}$ [95\% CI $-0.48,-0.15])$ and $2 \mathrm{~h}$ post-challenge-glucose $(-0.68 \mathrm{mmol} / \mathrm{1}[95 \% \mathrm{CI}-1.03,-0.34])$ compared with those in the usual care group [2, 15, 28-33, 35-37, 39]. No statistically significant difference in changes of fasting plasma glucose and $2 \mathrm{~h}$ post-challenge glucose test between men and women could be detected after 1 and 3 years (fasting plasma glucose: -0.40 vs $-0.08 \mathrm{mmol} / 1$ after 3 years, $p=0.09 ; 2 \mathrm{~h}$ post-challenge glucose: -0.78 vs $-0.62 \mathrm{mmol} / 1$ after 3 years, $p=0.65$ ).

\section{Glucose-lowering agents}

Five RCTs provided data on more than 3,800 men and 5,700 women to assess differences in the efficacy of acarbose, metformin, pioglitazone, rosiglitazone, and the combination of metformin and rosiglitazone between men and women [1, 20-22, 24]. All studies were placebo-controlled trials; mean follow-up periods varied from 2.4 to 3.9 years (see ESM Table 2). We were not able to obtain any information about adverse events, stratified by sex.

All five RCTs, with one study for each comparison, reported on type 2 diabetes incidence. Overall, no differences in the preventive effect of therapies with oral glucose-lowering agents between men and women could be detected. The intake of oral glucose-lowering drugs was associated with a reduction of type 2 diabetes. Detailed sex-specific results are illustrated in Table 1.

Diabetes-associated comorbidity and mortality Only one RCT, the CAnadian Normoglycemia Outcomes Evaluation (CANOE) trial provided sex-specific results of diabetesassociated morbidity after 3.9 years of study duration [21]. Owing to the limited observation time, only a few events were recorded. For example myocardial infarction was reported in 1 of 69 men and 0 of 138 women randomised to metformin and rosiglitazone or placebo (Table 1).

Lifestyle interventions vs metformin

Diabetes incidence Results of the United States Diabetes Prevention Program (US DPP) on 702 men and 1,395 women with prediabetes showed that out of 1,000 participants receiving 2.8 years of lifestyle intervention, at least 38 but up to 88 people can be prevented from progressing to type 2 diabetes, compared with metformin (RR 0.66 [95\% CI 0.54, 0.80]) [1, 40-47]. No differences in the preventive effect of lifestyle interventions could be detected between men and women (RR men 0.59 [95\% CI 0.41, 0.83]; RR women 0.70 [95\% CI 0.54, 0.89]).

The Indian Diabetes Prevention Program (IDPP-1) with 248 participants, receiving either lifestyle intervention or metformin, did not detect any statistically significant differences in type 2 diabetes incidence between interventions, neither in men nor in women (RR men 1.01 [95\% CI 0.74, 1.37]; RR women 0.61 [95\% CI $0.22,1.66])$ [48-51].

\section{Discussion}

To the best of our knowledge, this is the first systematic review that assessed potential sex-specific differences in effects of preventive interventions in prediabetic people. Overall, based on data of more than 5,500 men and 7,400 women, our review did not find any relevant sex-specific differences in treatment effects during 1 to 6 years of active interventions. In both sexes, lifestyle and pharmacological interventions had a beneficial preventive effect on the incidence of type 2 diabetes and weight gain.

Clinically, these findings highlight an important issue. Despite differences in age of onset, detection and burden of type 2 diabetes between men and women, the effectiveness of 
preventive interventions in people with prediabetes is not influenced by the sex. Consequently, clinicians and prevention managers can focus on factors that are known to determine the magnitude of beneficial effects, such as adherence. Several RCTs and observational studies have pointed out that longterm adherence to preventive interventions in prediabetic people can be a substantial challenge, especially when it comes to lifestyle interventions [30, 58]. Benefits of lifestyle interventions are greatest in those with the best adherence [58]. In the Finnish Diabetes Prevention Study (Finnish DPS) participants who achieved one of five predefined lifestyle goals had a $33 \%$ lower risk of progressing to type 2 diabetes compared with those who did not achieve any of the goals [59]. In highly motivated participants, who achieved five predefined goals, the risk reduction of type 2 diabetes incidence could be increased to $80 \%$. The proportion of participants in the lifestyle intervention group who achieved four or five predefined goals at the 3 year follow-up was only $14 \%$, despite the highly controlled environment of a clinical trial [30]. In routine clinical practice, the proportion of those not achieving permanent lifestyle changes is probably even greater, albeit with unclear consequences. Although a recent systematic review reported a rapid loss of beneficial effects on the onset of diabetes after lifestyle interventions have been stopped [60], some long-term observational data indicate that beneficial effects can be maintained for up to 23 years [59, 61, 62]. Despite such challenges, beneficial effects found in prevention trials are applicable to real world situations. Results of the Finnish DPS, for example, were also achieved at a population level in Finland [63]. Utilising positive reinforcements and selecting interventions based on individual preferences would therefore be important for personalised medicine and shared-decision making.

Successful prevention of diabetes also has an economic impact. Recent cost-effectiveness analyses indicate that lifestyle interventions are the most cost-effective approach [58, 64]. In people with prediabetes who are not able to adhere to lifestyle changes, initiation of metformin is probably the next best option, but thus far, no trial evidence confirms this for non-responders to lifestyle interventions.

The efficacy of lifestyle and pharmacological interventions for the prevention of type 2 diabetes has been assessed by other recently published systematic reviews [3, 58], but none of these studies evaluated sex-specific treatment effects.

Our systematic review has several limitations. First, a third of the eligible RCTs did not provide sex-specific data and could not be included in our meta-analyses. Given that we analysed data with consistent findings on more than 4,400 people with prediabetes, it seems unlikely that additional studies would substantially change our conclusions regarding similar benefits of lifestyle interventions for men and women with prediabetes to prevent further progress to type 2 diabetes. Second, the applicability to populations other than the ones included in trials is unclear. On average, participants in the trials were 45-60 years of age and ethnically diverse. Studies with Asian populations reported lower BMIs $\left(25-27 \mathrm{~kg} / \mathrm{m}^{2}\right)$ at baseline compared with their counterparts from European countries or the USA $\left(29-35 \mathrm{~kg} / \mathrm{m}^{2}\right)$. It is unclear whether findings can be extrapolated to younger or older populations or ethnic groups not included in the study populations. The only study that explored subgroup effects with respect to race was the US DPP. Authors reported that within the lifestyle treatment arm, black women experienced a significantly lower weight loss than black men and Hispanic or white participants $(p<0.01)$ [40]. Further studies need to assess whether lifestyle interventions have a different impact on women and men of different age and ethnic groups. Third, participants in some studies were recruited based on different definitions of prediabetes. Four (Da Qing, Finnish DPS, US DPP and Study to Prevent Non-Insulin Dependent Diabetes Mellitus [STOPNIDDM]) of the 12 trials recruited participants according to the WHO criteria from 1985, which used a higher threshold for fasting plasma glucose than current definitions [12]. Based on current definitions, some of the patients included in these four studies, therefore, would now be classified as persons with diabetes rather than prediabetes. All of the participants in these four studies, however, had to meet the same thresholds for $2 \mathrm{~h}$ post-challenge-glucose as participants in studies with current definitions of prediabetes. Despite differences in definitions, overall, population characteristics were similar across studies (ESM Table 2). Fourth, women with a history of gestational diabetes were included in some but not all trials. Studies that included women with gestational diabetes often failed to report the exact proportion of such women. Results of the US DPP, however, indicate similar risk reductions (49$50 \%$ ) with respect to progression to type 2 diabetes in women with and without a history of gestational diabetes after 3 years of lifestyle intervention [65]. Therefore, we are confident that the unknown proportions of women with a history of gestational diabetes in some studies did not substantially influence the results of our analyses. Fifth, we hardly found any data on sex-specific differences with respect to diabetes-related longterm complications, in particular cardiovascular disease and microvascular complications, or risk of harms. Observational studies on diabetes prevention analysing long-term complications of diabetes are rare [60] and were not analysed in our review. It is conceivable though that a reduction of the incidence of type 2 diabetes will lead to a reduction of long-term complications of the disease. The Da Qing study recently reported that, after 23 years of follow-up, $18 \%$ (47 of 259) of women and $41 \%$ (127 of 309) of men died. The risk of cardiovascular mortality (heart disease and stroke) was $72 \%$ lower for women in the lifestyle intervention arm (HR 0.28 [95\% CI 0.11, 0.71]) compared with those who received treatment as usual, while no differences between the male intervention and control groups were observed [62]. 
Finally, publication bias is a major concern for all systematic reviews. Despite extensive literature searches, we have no way to be sure we have detected all studies on type 2 diabetes prevention. Due to the small number of RCTs on the issue of type 2 diabetes prevention, the validity of statistical methods to explore publication bias, such as funnel plots, is limited.

In conclusion, our findings emphasise the importance of lifestyle interventions to prevent type 2 diabetes in men and women with prediabetes. Given similar effectiveness of interventions between men and women, clinicians need to focus on other aspects of sex-disparities such as the higher incidence of type 2 diabetes in middle-aged men and gaps in the quality of care between diabetic men and women.

Acknowledgements We wish to thank J. Hofmann (Danube University Krems, Krems, Austria) for administrative support. We also would like to thank the following authors for providing unpublished data on sexspecific results: G. Li and B. V. Howard (Da Qing); A. Ramachandran (IDPP-1); M. Watanabe and T. Saito (Zensharen); B. Zinman (CANOE); L. Penn (EDIPS); H. C. Gerstein (DREAM); J.-L. Chiasson and N. Yamamoto (STOP-NIDDM); G. D. Pimentel (Brazilian Lifestyle Intervention Study); J. Lindström (DPS); A. den Boer and E. E. Blaak (SLIM); and finally H. Pan (NIDDK repository, DPP) for providing sex-stratified results.

Funding The study was funded by the Medical-Scientific Fund of the Mayor of Vienna. The funding source had no role in the collection, analysis and interpretation of data, in the writing of the report, or in the decision to submit the article for publication.

Duality of interest JT has received research support from AstraZeneca, Boehringer Ingelheim, Merck Sharp \& Dohme, Novartis, Sanofi-Aventis and Servier and has acted as a consultant, advisory board member and/or speaker for AstraZeneca, Bayer Health Care, Ever Pharma, Novartis, Novo Nordisk, Sanofi-Aventis, Lilly, Merck Serono and Merck Sharp \& Dohme. AKW has acted as speaker or advisory board member for Astra Zeneca, Bristol-Myers Squibb, Merck Sharp \& Dohme, Novartis and Boehringer Ingelheim. All other authors declare that there is no duality of interest associated with their contribution to this manuscript.

Contribution statement All authors contributed to the planning of the study. AG devised the protocol for the review and coordinated the reviewing process. MVN conducted the literature search. AG, SR, JH, $\mathrm{AK}$ and AK-H conducted the screening of articles and extracted the data. AG and GG performed the statistical analysis. AG, JH, GG, JT and AKW wrote the manuscript. All authors read, critically revised and approved the final manuscript. AG is responsible for the integrity of the work as a whole.

\section{References}

1. Knowler WC, Barrett-Connor E, Fowler SE et al (2002) Reduction in the incidence of type 2 diabetes with lifestyle intervention or metformin. N Engl J Med 346:393-403

2. Lindström J, Eriksson JG, Valle TT et al (2003) Prevention of diabetes mellitus in subjects with impaired glucose tolerance in the Finnish Diabetes Prevention Study: results from a randomized clinical trial. J Am Soc Nephrol 14(7 Suppl 2):S108-S113
3. Hopper I, Billah B, Skiba M, Krum H (2011) Prevention of diabetes and reduction in major cardiovascular events in studies of subjects with prediabetes: meta-analysis of randomised controlled clinical trials. Eur J Cardiovasc Prev Rehabil 18:813-823

4. Gerstein HC, Bosch J, Dagenais GR et al (2012) Basal insulin and cardiovascular and other outcomes in dysglycemia. N Engl J Med 367:319-328

5. Qiao Q, Hu G, Tuomilehto J et al (2003) Age- and sex-specific prevalence of diabetes and impaired glucose regulation in 11 Asian cohorts. Diabetes Care 26:1770-1780

6. (2003) Age- and sex-specific prevalences of diabetes and impaired glucose regulation in 13 European cohorts. Diabetes Care 26:61-69

7. Williams JW, Zimmet PZ, Shaw JE et al (2003) Gender differences in the prevalence of impaired fasting glycaemia and impaired glucose tolerance in Mauritius. Does sex matter? Diabet Med 20:915-920

8. Clausen JO, Borch-Johnsen K, Ibsen H et al (1996) Insulin sensitivity index, acute insulin response, and glucose effectiveness in a population-based sample of 380 young healthy Caucasians. Analysis of the impact of gender, body fat, physical fitness, and life-style factors. J Clin Invest 98:1195-1209

9. Chapman AL, Morgan LC, Gartlehner G (2010) Semi-automating the manual literature search for systematic reviews increases efficiency. Health Inf Libr J 27:22-27

10. The Expert Committee on the Diagnosis and Classification of Diabetes Mellitus (1997) Report of the expert committee on the diagnosis and classification of diabetes mellitus. Diabetes Care 20: 1183-1197

11. The Expert Committee on the Diagnosis and Classification of Diabetes Mellitus (2003) Report of the expert committee on the diagnosis and classification of diabetes mellitus. Diabetes Care 26(Suppl 1):S5-S20

12. World Health Organization (1985) Diabetes mellitus - report of a WHO Study Group. WHO, Geneva, pp 113

13. Chiasson JL, Josse RG, Gomis R, Hanefeld M, Karasik A, Laakso M (2003) Acarbose treatment and the risk of cardiovascular disease and hypertension in patients with impaired glucose tolerance: the STOPNIDDM trial. JAMA 290:486-494

14. Pan XR, Hu YH, Li GW, Liu PA, Bennett PH, Howard BV (1993) Impaired glucose tolerance and its relationship to ECG-indicated coronary heart disease and risk factors among Chinese. Da Qing IGT and diabetes study. Diabetes Care 16:150-156

15. Eriksson J, Lindström J, Valle T et al (1999) Prevention of Type II diabetes in subjects with impaired glucose tolerance: The Diabetes Prevention Study (DPS) in Finland. Study design and 1-year interim report on the feasibility of the lifestyle intervention programme. Diabetologia 42:793-801

16. The Diabetes Prevention Program Research Group (1999) The Diabetes Prevention Program. Design and methods for a clinical trial in the prevention of type 2 diabetes. Diabetes Care 22:623-634

17. Higgins JPT, Green S (eds) (2011) Cochrane handbook for systematic reviews of interventions 5.1.0 [updated March 2011]. The Cochrane Collaboration. Available from www. Cochrane-handbook.org

18. Balshem H, Helfand M, Schünemann $\mathrm{H}$ et al (2011) GRADE guidelines: 3. Rating the quality of evidence. J Clin Epidemiol 64:401-406

19. Hanefeld M, Karasik A, Koehler C, Westermeier T, Chiasson JL (2009) Metabolic syndrome and its single traits as risk factors for diabetes in people with impaired glucose tolerance: the STOPNIDDM trial. Diab Vasc Dis Res 6:32-37

20. Chiasson JL, Josse RG, Gomis R, Hanefeld M, Karasik A, Laakso M (2002) Acarbose for prevention of type 2 diabetes mellitus: the STOP-NIDDM randomised trial. Lancet 359:2072-2077

21. Zinman B, Harris SB, Neuman J et al (2010) Low-dose combination therapy with rosiglitazone and metformin to prevent type 2 diabetes mellitus (CANOE trial): a double-blind randomised controlled study. Lancet 376:103-111 
22. DeFronzo RA, Tripathy D, Schwenke DC et al (2011) Pioglitazone for diabetes prevention in impaired glucose tolerance. N Engl J Med 364:1104-1115

23. Boyko EJ, Gerstein HC, Mohan Vet al (2010) Effects of ethnicity on diabetes incidence and prevention: results of the Diabetes REduction Assessment with ramipril and rosiglitazone Medication (DREAM) trial. Diabet Med 27:1226-1232

24. Gerstein HC, Yusuf S, Bosch J et al (2006) Effect of rosiglitazone on the frequency of diabetes in patients with impaired glucose tolerance or impaired fasting glucose: a randomised controlled trial. Lancet 368:1096-1105

25. Dagenais GR, Gerstein HC, Holman R, et al (2008) Effects of ramipril and rosiglitazone on cardiovascular and renal outcomes in people with impaired glucose tolerance or impaired fasting glucose: results of the Diabetes REduction Assessment with ramipril and rosiglitazone Medication (DREAM) trial. Diabetes Care: 1007-1014

26. Gong Q, Gregg EW, Wang J et al (2011) Long-term effects of a randomised trial of a 6-year lifestyle intervention in impaired glucose tolerance on diabetes-related microvascular complications: the China Da Qing Diabetes Prevention Outcome Study. Diabetologia 54:300 307

27. Pan XR, Li GW, Hu YH et al (1997) Effects of diet and exercise in preventing NIDDM in people with impaired glucose tolerance. The Da Qing IGT and Diabetes Study. Diabetes Care 20:537-544

28. Lindström J, Peltonen M, Eriksson JG et al (2008) Determinants for the effectiveness of lifestyle intervention in the Finnish Diabetes Prevention Study. Diabetes Care 31:857-862

29. Ilanne-Parikka P, Eriksson JG, Lindström J et al (2008) Effect of lifestyle intervention on the occurrence of metabolic syndrome and its components in the Finnish Diabetes Prevention Study. Diabetes Care $31: 805-807$

30. Lindström J, Ilanne-Parikka P, Peltonen M et al (2006) Sustained reduction in the incidence of type 2 diabetes by lifestyle intervention: follow-up of the Finnish Diabetes Prevention Study. Lancet 368: 1673-1679

31. Lindström J, Louheranta A, Mannelin M et al (2003) The Finnish Diabetes Prevention Study (DPS): lifestyle intervention and 3year results on diet and physical activity. Diabetes Care 26: 3230-3236

32. Tuomilehto J, Lindström J, Eriksson JG et al (2001) Prevention of type 2 diabetes mellitus by changes in lifestyle among subjects with impaired glucose tolerance. N Engl J Med 344:1343-1350

33. Uusitupa M, Lindi V, Louheranta A, Salopuro T, Lindström J, Tuomilehto J (2003) Long-term improvement in insulin sensitivity by changing lifestyles of people with impaired glucose tolerance: 4year results from the Finnish Diabetes Prevention Study. Diabetes 52: 2532-2538

34. Saito T, Watanabe M, Nishida J et al (2011) Lifestyle modification and prevention of type 2 diabetes in overweight Japanese with impaired fasting glucose levels: a randomized controlled trial. Arch Intern Med 171:1352-1360

35. Corpeleijn E, Feskens EJ, Jansen EH et al (2006) Improvements in glucose tolerance and insulin sensitivity after lifestyle intervention are related to changes in serum fatty acid profile and desaturase activities: the SLIM study. Diabetologia 49:2392-2401

36. Roumen C, Corpeleijn E, Feskens EJ, Mensink M, Saris WH, Blaak EE (2008) Impact of 3-year lifestyle intervention on postprandial glucose metabolism: the SLIM study. Diabet Med 25:597-605

37. Roumen C, Feskens EJ, Corpeleijn E, Mensink M, Saris WH, Blaak EE (2011) Predictors of lifestyle intervention outcome and dropout: the SLIM study. Eur J Clin Nutr 65:1141-1147

38. Pimentel GD, Portero-McLellan KC, Oliveira EP et al (2010) Longterm nutrition education reduces several risk factors for type 2 diabetes mellitus in Brazilians with impaired glucose tolerance. Nutr Res 30:186-190
39. Penn L, White M, Oldroyd J, Walker M, Alberti KG, Mathers JC (2009) Prevention of type 2 diabetes in adults with impaired glucose tolerance: the European Diabetes Prevention RCT in Newcastle upon Tyne, UK. BMC Public Health 9:342

40. West DS, Elaine Prewitt T, Bursac Z, Felix HC (2008) Weight loss of black, white, and Hispanic men and women in the Diabetes Prevention Program. Obesity (Silver Spring) 16:1413-1420

41. Crandall J, Schade D, Ma Y et al (2006) The influence of age on the effects of lifestyle modification and metformin in prevention of diabetes. J Gerontol A Biol Sci Med Sci 61:1075-1081

42. Brown JS, Wing R, Barrett-Connor E et al (2006) Lifestyle intervention is associated with lower prevalence of urinary incontinence: the Diabetes Prevention Program. Diabetes Care 29:385-390

43. Knowler WC, Hamman RF, Edelstein SL et al (2005) Prevention of type 2 diabetes with troglitazone in the Diabetes Prevention Program. Diabetes 54:1150-1156

44. Molitch ME, Fujimoto W, Hamman RF, Knowler WC (2003) The diabetes prevention program and its global implications. J Am Soc Nephrol 14(7 Suppl 2):S103-S107

45. Florez H, Pan Q, Ackermann RT et al (2012) Impact of lifestyle intervention and metformin on health-related quality of life: the Diabetes Prevention Program Randomized Trial. J Gen Intern Med 27:1594-1601

46. Perreault L, Ma Y, Dagogo-Jack S et al (2008) Sex differences in diabetes risk and the effect of intensive lifestyle modification in the diabetes prevention program. Diabetes Care 31:1416-1421

47. Diabetes Prevention Program Research Group (2012) Long-term safety, tolerability, and weight loss associated with metformin in the Diabetes Prevention Program Outcomes Study. Diabetes Care 35:731-737

48. Ramachandran A, Arun N, Shetty AS, Snehalatha C (2010) Efficacy of primary prevention interventions when fasting and postglucose dysglycemia coexist: analysis of the Indian Diabetes Prevention Programmes (IDPP-1 and IDPP-2). Diabetes Care 33:2164-2168

49. Snehalatha C, Mary S, Selvam S et al (2009) Changes in insulin secretion and insulin sensitivity in relation to the glycemic outcomes in subjects with impaired glucose tolerance in the Indian Diabetes Prevention Programme-1 (IDPP-1). Diabetes Care 32:1796-1801

50. Snehalatha C, Mary S, Joshi VV, Ramachandran A (2008) Beneficial effects of strategies for primary prevention of diabetes on cardiovascular risk factors: results of the Indian Diabetes Prevention Programme. Diabetes Vasc Dis Res 5:25-29

51. Ramachandran A, Snehalatha C, Mary S, Mukesh B, Bhaskar AD, Vijay V (2006) The Indian Diabetes Prevention Programme shows that lifestyle modification and metformin prevent type 2 diabetes in Asian Indian subjects with impaired glucose tolerance (IDPP-1). Diabetologia 49:289-297

52. Sakane N, Sato J, Tsushita K et al (2011) Prevention of type 2 diabetes in a primary healthcare setting: three-year results of lifestyle intervention in Japanese subjects with impaired glucose tolerance. BMC Public Health 11:40

53. Fontbonne A, Diouf I, Baccara-Dinet M, Eschwege E, Charles MA (2009) Effects of 1-year treatment with metformin on metabolic and cardiovascular risk factors in non-diabetic upper-body obese subjects with mild glucose anomalies: a post-hoc analysis of the BIGPRO1 trial. Diabetes Metab 35:385-391

54. Kawamori R, Tajima N, Iwamoto Y, Kashiwagi A, Shimamoto K, Kaku K (2009) Voglibose for prevention of type 2 diabetes mellitus: a randomised, double-blind trial in Japanese individuals with impaired glucose tolerance. Lancet 373:1607-1614

55. Oldroyd JC, Unwin NC, White M, Mathers JC, Alberti KG (2006) Randomised controlled trial evaluating lifestyle interventions in people with impaired glucose tolerance. Diabetes Res Clin Pract 72:117-127

56. Li CL, Pan CY, Lu JM et al (1999) Effect of metformin on patients with impaired glucose tolerance. Diabet Med 16:477-481

57. Nijpels G, Boorsma W, Dekker JM, Kostense PJ, Bouter LM, Heine RJ (2008) A study of the effects of acarbose on glucose metabolism 
in patients predisposed to developing diabetes: the Dutch acarbose intervention study in persons with impaired glucose tolerance (DAISI). Diabetes Metab Res Rev 24:611-616

58. Gillett M, Royle P, Snaith A et al (2012) Non-pharmacological interventions to reduce the risk of diabetes in people with impaired glucose regulation: a systematic review and economic evaluation. Health Technol Assess 16:1-236, iii-iv

59. Lindström J, Peltonen M, Eriksson JG et al (2013) Improved lifestyle and decreased diabetes risk over 13 years: long-term follow-up of the randomised Finnish Diabetes Prevention Study (DPS). Diabetologia $56: 284-293$

60. Yoon U, Kwok LL, Magkidis A (2013) Efficacy of lifestyle interventions in reducing diabetes incidence in patients with impaired glucose tolerance: a systematic review of randomized controlled trials. Metabolism 62:303-314

61. Knowler WC, Fowler SE, Hamman RF et al (2009) 10-year follow-up of diabetes incidence and weight loss in the
Diabetes Prevention Program Outcomes Study. Lancet 374: 1677-1686

62. Li G, Zhang P, Wang J et al (2014) Cardiovascular mortality, all-cause mortality, and diabetes incidence after lifestyle intervention for people with impaired glucose tolerance in the Da Qing Diabetes Prevention Study: a 23-year follow-up study. Lancet Diabetes Endocrinol 2:474-480

63. Tuomilehto J, Schwarz P, Lindström J (2011) Long-term benefits from lifestyle interventions for type 2 diabetes prevention: time to expand the efforts. Diabetes Care 34(Suppl 2):S210-S214

64. Herman WH, Edelstein SL, Ratner RE et al (2013) Effectiveness and cost-effectiveness of diabetes prevention among adherent participants. Am J Manag Care 19:194-202

65. Ratner RE, Christophi CA, Metzger BE et al (2008) Prevention of diabetes in women with a history of gestational diabetes: effects of metformin and lifestyle interventions. J Clin Endocrinol Metab 93: 4774-4779 